Año 16, Vol. 11, número 21, agosto-diciembre 2021

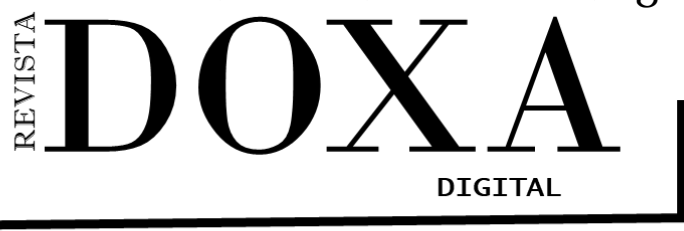

eISSN: 2594-2786
Sección: Ciencias Administrativas

Recibido: Agosto 2021

Aceptado: Octubre 2021

DOI: $10.52191 /$ rdojs.2021.231

Pág.: 95-111

\title{
El derecho de alumbrado público en el Municipio de Juárez, Chihuahua, México
}

The street lighting law in the Municipality of Juarez,

Chihuahua, Mexico

Ismael Narciso Jiménez * y Luis Carlos Romero Rodríguez **

\section{RESUMEN}

El principal objetivo de este trabajo de investigación es la necesidad de exponer los problemas legales, financieros y fiscales del "Derecho al Alumbrado Público" (DAP) que enfrentan los Municipios al momento de realizar los cobros correspondientes en esta área, en este caso específico el Municipio de Juárez, Chihuahua, México. Pero con estricto apego a los criterios científico-técnicos de la normatividad fiscal de nuestro Estado Mexicano, sin violar el Estado de Derecho, a fin de lograr una buena administración y gestión de cobranza en el ramo del Derecho de Alumbrado Público.

PALABRAS CLAVE: Derecho, alumbrado público, fiscalización, Juárez

\begin{abstract}
The main objective of this research paper is the need to expose the legal, financial and fiscal problems of the "Right to Public Lighting" (RPL) faced by the Municipalities when making the corresponding charges in this area, in this specific case the Municipality of Juárez, Chihuahua, Mexico. But with strict adherence to the scientific-technical criteria of the fiscal regulations of our Mexican State, without violating the Rule of Law, in order to achieve good administration and collection management in the field of Public Lighting Law.
\end{abstract}

KEY WORDS: Law, Street Lighting, taxation, Juarez,

\footnotetext{
*Autor para correspondencia. Maestra en Derecho fiscal,, profesor investigador adscrito a la Universidad Tecnológica de Ciudad Juárez. Contacto: jimenez163379@gmail.com

** Maestro en administración, profesor investigador adscrito a la Universidad Tecnológica de Ciudad Juárez Contacto:: lcromerorod@gmail.com
} 
Año 16, Vol. 11, número 21, agosto-diciembre Sección: Ciencias Administrativas

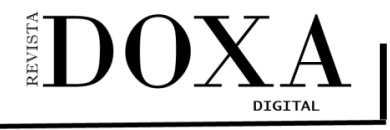

DOI: $10.52191 /$ rdojs.2021.231

Pág.:95-111
Ismael Narciso Jiménez y

Luis Carlos Romero Rodríguez

El derecho al alumbrado público ...

\section{Introducción}

El presente trabajo de investigación tiene como objetivo primordial la necesidad de exponer la problemática jurídica, financiera y fiscal del "Derecho de Alumbrado Público (DAP) a la que se enfrentan los Municipios en el momento de realizar los cobros correspondientes en este rubro, en este caso específico el Municipio de Juárez, Chihuahua, México.

Se plantea situaciones de hecho jurídico que deben prever los sujetos activos en el momento de crear los instrumentos jurídicos que harán posible la recaudación de recursos monetarios. De igual forma se analiza los principios jurídicos doctrinarios a los cuáles deben sujetarse toda norma jurídica impositiva. También se hace un análisis respecto de los principios legalidad, proporcionalidad y equidad tributaria que deben de contemplar los gobiernos en el momento de definir de manera específica los ingresos que han de cobrar, en este caso específico el Municipio de Juárez, en estricto apego a los principios y normas jurídicas tributarias.

Por último, se hace a modo de conclusión las recomendaciones y adaptaciones que deberá realizar el Municipio de Juárez a sus normas respectivas ya que por ende el Derecho al cobro por concepto de Alumbrado Público le asiste. Pero deberá observar y aplicar los criterios técnicos científicos de las normas fiscales en nuestro Estado Mexicano, sin violentar el Estado de Derecho, con el objeto de lograr una buena administración y gestión de cobro en materia de Derecho de Alumbrado Público.

\section{Generalidades, objetivos, definición de conceptos y ubicación del Municipio de Juárez}

Es indudable que el alumbrado público en pleno siglo XXI es imprescindible en este mundo cada vez más globalizado para garantizar a los transeúntes y automovilistas sus tareas y/o actividades diarias de manera correcta, visible y sin temor alguno, ya que contribuye hasta cierto punto a la seguridad de las personas, ya que el lugar iluminado desalienta robos y crímenes.

Abundando; Jasso (2015) parafrasea a Jane Jacobs (1973) respecto de su obra "Muerte y vi-

da de las grandes ciudades" y afirma en su tesis titulada ¿Por qué la gente se siente insegura en el espacio público?, misma que presenta para obtener el grado de Doctora en Políticas Públicas del Centro de Investigación y Docencia Económicas, A. C. que forma parte del sistema de Centros Públicos de Investigación del Consejo Nacional de Ciencia y Tecnología (CONACYT), lo siguiente:

En relación al alumbrado público que generalmente se ha considerado como un factor para prevenir el delito y generar una percepción de seguridad, refiere que la oscuridad no es por sí sola la que hace inseguro un lugar, así como tampoco la iluminación lo vuelve seguro, sin embargo, se- 
Año 16, Vol. 11, número 21, agosto-diciembre Sección: Ciencias Administrativas

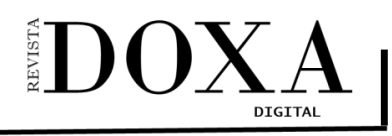

DOI: $10.52191 /$ rdojs.2021.231

Pág.:95-111
Ismael Narciso Jiménez y

Luis Carlos Romero Rodríguez

El derecho al alumbrado público ...

ñala "es obvio que una excelente iluminación aumenta las posibilidades de cada para de ojos, ya que su alcance es mayor" (Jacobs, 1973:13) en la medida en la que se propicie la visibilidad para la vigilancia informal, habrá mayor posibilidad de seguridad. Jasso (2015).

Por lo antes expuesto, es indudable e imprescindible la importancia que representa el tema del Alumbrado Público para las grandes ciudades, en este caso específico al Municipio de Juárez, Chihuahua, México.

\section{Objetivo}

Por esta razón el presente trabajo de investigación tiene como objetivo primordial la necesidad de exponer la problemática jurídica, financiera y fiscal del "Derecho de Alumbrado Público" en el Municipio de Juárez, Chihuahua, México, como ente gubernamental responsable por mandato Constitucional de proveer el servicio en este municipio.

\section{Definición de conceptos}

Entendiendo como "derecho" objeto de estudio del presente lo especificado por el Código Fiscal de la Federación (CFF), en su artículo $2^{\circ}$, fracción IV, que define el concepto como sigue:

"Derechos son las contribuciones establecidas en Ley por el uso o aprovechamiento de los bienes del dominio público de la Nación, así como por recibir servicios que presta el Estado en sus funciones de derecho público."

Esclareciendo el significado de los conceptos como tal la Real Academia Española (2021) define "alumbrado" como el conjunto de luces que alumbran un espacio, especialmente una vía o lugares públicos".

Por otro lado, el diccionario Definición ABC (2021) de la web específica: "podremos referir a la serie de luces o al sistema especialmente destinado para aportarle iluminación a un espacio"

Aunado al concepto de "público" al referirse a un ente económico perteneciente a la esfera gubernamental catalogado como tercer nivel de gobierno dentro del Estado Mexicano.

\section{Ubicación del Municipio de Juárez}

Con el objeto de precisar, ubicar y/o localizar al Municipio de Juárez geográficamente como uno de los 67 municipios del Estado de Chihuahua.

El Municipio de Juárez se encuentra localizado en el extremo norte del estado de Chihuahua y en la limita Frontera entre Estados Unidos y México, sus coordenadas geográficas extremas son $31^{\circ}$ 
Año 16, Vol. 11, número 21, agosto-diciembre Sección: Ciencias Administrativas

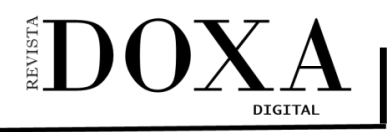

DOI: $10.52191 /$ rdojs.2021.231

Pág.:95-111
Ismael Narciso Jiménez y

Luis Carlos Romero Rodríguez

El derecho al alumbrado público ...

$07^{\prime}-31^{\circ} 48^{\prime}$ de latitud norte y $106^{\circ} 10^{\prime}-106^{\circ} 58^{\prime}$ de longitud oeste y su altitud fluctúa entre un máximo de 1900 y un mínimo de 1000 metros sobre el nivel del mar. Su extensión territorial es de 3561.14 kilómetros cuadrados que representan un $1.44 \%$ de la superficie total del estado de Chihuahua (Municipio de Juárez, 2021).

\section{El Derecho de Alumbrado Público}

\section{Fundamento Constitucional}

Si bien sabemos que el alumbrado público es un servicio que deben de prestar y garantizar los municipios; en estricto acatamiento al artículo 115, fracción III de la Constitución Política de los Estados Unidos Mexicanos (CPEUM) que establece: "Los Municipios tendrán a su cargo las funciones y servicios públicos siguientes: ...Alumbrado público...."

Luego entonces; en este caso específico el Municipio de Juárez no es la excepción.

\section{Fundamento Constitucional del Derecho Fiscal}

El derecho fiscal como rama del derecho administrativo y disciplina jurídica encargada del estudio de la aplicación de las normas jurídicas tributarias a través de las cuáles el Estado (Federación, Ciudad de México, Entidades Federativas y Municipios) ejerce su facultad económico coactiva (poder y/o potestad tributarios) sobre los sujetos pasivos (contribuyentes o particulares), como medio para allegarse de ingresos o recursos pecuniarios que le servirán para sufragar el gasto público en aras de la consecución del bien común y la prestación de los servicios públicos que le atañen, de conformidad a lo estipulado en nuestra CPEUM en su artículo 31, fracción IV, como sigue:

\section{Artículo 31. Son obligaciones de los mexicanos:}

IV. Contribuir para los gastos públicos, así de la Federación, como de los Estados, de la Ciudad de México y del Municipio en que residan, de la manera proporcional y equitativa que dispongan las leyes.

De esta manera el Derecho de Alumbrado Público (DAP) al estar encuadrado en el ámbito tributario por el artículo $2^{\circ}$ del Código Fiscal de la Federación, cobra relevancia en materia fiscal al darle el tratamiento como tal, mismo que ha sido objeto de análisis en el punto 1.2 de este documento, ya que se trata de ingresos o recursos pecuniarios de los cuáles el Municipio de Juárez habrá de recaudar durante el ejercicio fiscal correspondiente para efectos de sufragar sus gastos pú- 
Año 16, Vol. 11, número 21, agosto-diciembre Sección: Ciencias Administrativas

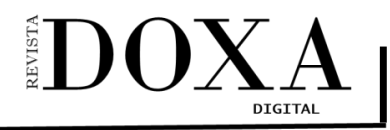

DOI: 10.52191/rdojs.2021.231

Pág.:95-111
Ismael Narciso Jiménez y

Luis Carlos Romero Rodríguez

El derecho al alumbrado público ...

blicos en es-

te ámbito, al tratarse de una materia de orden público y de interés general.

\section{Ley de Ingresos del Municipio de Juárez, Chihuahua, Ejercicio Fiscal 2021}

Según el anexo publicado en el periódico oficial del Estado de Chihuahua el miércoles 13 de enero de 2021 de Ley de Ingresos del Municipio de Juárez, Chihuahua, (2021) el Municipio de Juárez pronosticó un monto global en su recaudación de ingresos por concepto de "Derechos", la cantidad de $\$ 573,613,628.32$ (Quinientos setenta y tres millones seiscientos trece mil seiscientos veintiocho pesos 32/100 moneda nacional) sin definir un monto específico por concepto del Derecho de Alumbrado Público.

\section{Planteamiento de la problemática}

El artículo 47 de Ley de Ingresos del Municipio de Juárez, Chihuahua para el Ejercicio Fiscal 2021 establece las cuotas impositivas para los sujetos acreedores de este Derecho de un modo arbitrario, sin ningún apego al Estado de Derecho y principios jurídicos doctrinarios fiscales, técnicos y científicos. Violentando de esta forma el artículo 31, fracción IV de nuestra CPEUM, como norma primaria y máxima de todo lo relacionado con los aspectos tributarios, al no establecer y definir cri-

Tabla 1.- Tarifa o cuotas de imposición por el Derecho de Alumbrado Público en el Municipio de Juárez

\begin{tabular}{lcc}
\hline \multicolumn{1}{c}{ Tipo de predio } & $\begin{array}{c}\text { Cuota DAP Bimestral } \\
\text { (cifras en pesos) }\end{array}$ & $\begin{array}{c}\text { Cuota DAP Mensual } \\
\text { (cifras en pesos) }\end{array}$ \\
\hline Habitacional & $\$ 40.00$ & $\$ 20.00$ \\
Habitacional alto & $\$ 120.00$ & $\$ 60.00$ \\
Habitacional consumo especial & $\$ 800.00$ & $\$ 400.00$ \\
Industria pequeña & $\$ 1,400.00$ & $\$ 700.00$ \\
Industrial ligera I & $\$ 2,400.00$ & $\$ 1,200.00$ \\
Industrial ligera II & $\$ 3,500.00$ & $\$ 1,750.00$ \\
Industrial ligera III & $\$ 5,000.00$ & $\$ 2,500.00$ \\
Industrial mediana I & $\$ 10,000.00$ & $\$ 5,000.00$ \\
Industrial mediana II & $\$ 15,000.00$ & $\$ 7,500.00$ \\
Industrial mediana III & $\$ 20,000.00$ & $\$ 10,000.00$ \\
Industrial alta & $\$ 40,000.00$ & $\$ 20,000.00$ \\
Sistemas de bombeo de aguas potables y & $\$ 2,300.00$ & $\$ 1,150.00$ \\
residuales & $\$ 120.00$ & $\$ 60.00$ \\
Comercio pequeño & $\$ 240.00$ & $\$ 120.00$ \\
Comercio mediano bajo & $\$ 400.00$ & $\$ 200.00$ \\
Comercio mediano & $\$ 800.00$ & $\$ 400.00$ \\
Comercio mediano alto & $\$ 2,300.00$ & $\$ 1,150.00$ \\
Comercio alto & $\$ 100.00$ & $\$ 50.00$ \\
\hline Terreno baldío / predio rustico & & \\
\hline
\end{tabular}

Fuente: Elaboración propia a partir de datos consultados en la Ley de Ingresos del Municipio de Juárez para el ejercicio fiscal 2021 
Año 16, Vol. 11, número 21, agosto-diciembre Sección: Ciencias Administrativas

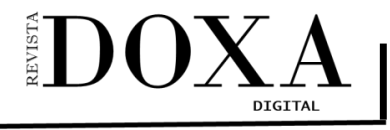

DOI: 10.52191/rdojs.2021.231

Pág.:95-111
Ismael Narciso Jiménez y

Luis Carlos Romero Rodríguez

El derecho al alumbrado público ...

terios de proporcionalidad y equidad en sus cuotas impositivas mismas que serán objeto de análisis y controversia, se presenta las cuotas impositivas en comento en la tabla 1.

\section{Violación al "Principio de Legalidad Tributaria"}

Conforme a la aplicación de dicho principio en "stricto sensu" no es suficiente que las normas jurídicas primarias prevean o estipulen tales situaciones, como sucede en este caso. Los artículos 31, fracción IV y 115, fracción III ambos Constitucionales, envisten jurídicamente al Municipio de Juárez dentro de su ámbito de competencia las atribuciones, facultades y funciones fundamentales necesarias para llevar a cabo dicha prestación del servicio de alumbrado público.

De igual forma el segundo párrafo del artículo 175 del Código Municipal para el Estado de Chihuahua como norma secundaria delimita en forma clara y específica los sujetos pasivos de este Derecho, que a la letra dice:

...Son sujetos de este derecho, las personas o instancias propietarias o poseedoras de predios, ya sean urbanos, semiurbanos o rústicos, ubicados en el área territorial del municipio.

No obstante, la norma fiscal fundamental que le da origen o la facultad de realizar el cobro correspondiente al Municipio de Juárez en este rubro es el artículo 47 de la "Ley de Ingresos del Municipio de Juárez para el ejercicio fiscal 2021".

Actualmente dicha ley conforme a su redacción actual no precisa de forma clara y concluyente los sujetos acreedores de este derecho al fijar una tabla de clasificación de cuotas fijas por "tipo de predio" sin delimitar en forma concreta los sujetos pasivos, mismo que ha sido objeto de análisis en párrafos anteriores. Violentando así; contundentemente el "principio de jerarquía de leyes" que se encuentra previsto en el artículo 133 de la Constitución Política de los Estados Unidos Mexicanos, que a la letra especifica:

Esta Constitución, las leyes del Congreso de la Unión que emanen de ella y todos los tratados que estén de acuerdo con la misma, celebrados y que se celebren por el Presidente de la República, con aprobación del Senado, serán la Ley Suprema de toda la Unión. Los jueces de cada entidad federativa se arreglarán a dicha Constitución, leyes y tratados, a pesar de las disposiciones en contrario que pueda haber en las Constituciones o leyes de las entidades federativas. (CPEUM, 2021).

Asociando la insistencia de lo mencionado en el párrafo anterior. En concordancia la primera sala de la Suprema Corte de Justicia de la Nación (SCJN) ha reiterado en su tesis aislada Constitu- 
Año 16, Vol. 11, número 21, agosto-diciembre Sección: Ciencias Administrativas

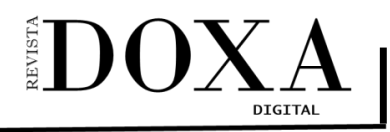

DOI: $10.52191 /$ rdojs.2021.231

Pág.:95-111
Ismael Narciso Jiménez y

Luis Carlos Romero Rodríguez

El derecho al alumbrado público ...

cional No. 2016003, décima época, publicado el viernes 19 de enero de 2018 a las 10:20 horas en el Semanario Judicial de la Federación lo subsecuente:

"RESPONSABILIDAD PATRIMONIAL DEL ESTADO OBJETIVA Y DIRECTA. LA FALTA DE ADECUACIÓN EN LAS LEGISLATURAS LOCALES CONSTITUYE UNA VIOLACIÓN AL PRINCIPIO DE SUPREMACÍA CONSTITUCIONAL PREVISTO EN EL ARTÍCULO 133 CONSTITUCIONAL.

El artículo 133 prevé dos dimensiones que rigen el sistema constitucional: 1) la supremacía de la Constitución Política de los Estados Unidos Mexicanos, y; 2) la jerarquía normativa en el Estado Mexicano que conforman la Constitución, las leyes que emanen de ésta y que expida el Congreso de la Unión y los tratados internacionales de los que el Estado Mexicano sea parte y la Ley Suprema de la Unión. Así, las constituciones y las leyes de las entidades federativas, con independencia de la soberanía de los Estados que protege el artículo 40 constitucional para los asuntos concernientes a su régimen interno, deberán observar los mandatos constitucionales $y$, por lo tanto, no vulnerarlos; es decir, si las leyes expedidas por las Legislaturas Locales resultan contrarias a los preceptos constitucionales, deben predominar las disposiciones de la Norma Fundamental y no las de esas leyes ordinarias, aun cuando procedan de su Constitución local, incluso cuando se trate directamente de esta última. Luego, si una entidad federativa no adecuó su normatividad a la obligación que impuso el artículo 113, párrafo segundo, de la Constitución General vigente a partir del 10. de enero de 2014 (actualmente 109, último párrafo, según Decreto por el que se reforman, adicionan y derogan diversas disposiciones de la Constitución Política de los Estados Unidos Mexicanos, en materia de combate a la corrupción, publicado en el Diario Oficial de la Federación el 27 de mayo de 2015), en relación con la responsabilidad objetiva y directa en que puede incurrir el Estado y que genera la indemnización a los particulares por los daños que puedan sufrir a sus bienes o derechos, con motivo de la actividad administrativa irregular, esa circunstancia deriva en una violación al principio de supremacía constitucional que tutela el artículo 133 constitucional.

Amparo directo en revisión 6718/2016. 14 de junio de 2017. Cinco votos de los Ministros Arturo Zaldívar Lelo de Larrea, José Ramón Cossío Díaz, quien reservó su derecho para formular voto concurrente, Jorge Mario Pardo Rebolledo, Alfredo Gutiérrez Ortiz Mena y Norma Lucía Piña Hernández. Ponente: Alfredo Gutiérrez Ortiz Mena. Secretaria: Gabriela Eleonora Cortés Araujo." (SCJN, 2018). 
Año 16, Vol. 11, número 21, agosto-diciembre Sección: Ciencias Administrativas

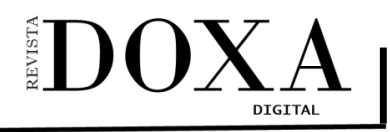

DOI: 10.52191/rdojs.2021.231

Pág.:95-111
Ismael Narciso Jiménez y

Luis Carlos Romero Rodríguez

El derecho al alumbrado público ...

Abundando; en materia de interpretación fiscal, el primer párrafo del artículo $5^{\circ}$ del Código Fiscal de la Federación (CFF) señala:

Las disposiciones fiscales que establezcan cargas a los particulares y las que señalan excepciones a las mismas, así como las que fijan las infracciones y sanciones, son de aplicación estricta. Se considera que establecen cargas a los particulares las normas que se refieren al sujeto, objeto, base, tasa o tarifa.

Las otras disposiciones fiscales se interpretarán aplicando cualquier método de interpretación jurídica. A falta de norma fiscal expresa, se aplicarán supletoriamente las disposiciones del derecho federal común cuando su aplicación no sea contraria a la naturaleza propia del derecho fiscal." (CFF, 2021).

Luego entonces; para todos los efectos legales no se puede dejar al arbitrio la interpretación de la norma jurídica; ya que al tratarse de uno de los elementos constitutivos fundamentales de toda norma fiscal debe de ser clara y precisa en la delimitación de los sujetos pasivos, en estricto acatamiento al Principio de Legalidad de que la autoridad solo puede hacer lo que la ley le faculta y considerando al Municipio de Juárez como orden de gobierno que debe sujetarse a la observancia plena e irrestricta del Estado de Derecho, debe precisar a ciencia cierta la redacción de la norma correspondiente.

A modo de ejemplo; podemos señalar el artículo $1^{\circ}$ de la Ley del Impuesto al valor Agregado (IVA), que a la letra dice:

Están obligadas al pago del impuesto al valor agregado establecido en esta Ley, las personas físicas y las morales que, en territorio nacional, realicen los actos o actividades siguientes:

I.- Enajenen bienes.

II.- Presten servicios independientes.

III.- Otorguen el uso o goce temporal de bienes.

IV.- Importen bienes o servicios. Ley del IVA (2021).

De lo anterior podemos observar que la redacción de la norma es clara y precisa al considerar tecnicismos que delimitan a los sujetos pasivos sin dar a la interpretación más alcance que el que naturalmente tiene, es decir; delimita a la perfección los sujetos pasivos acreedores de este impuesto en un sentido estricto y literal.

\section{Violación al principio de Proporcionalidad Tributaria}


Año 16, Vol. 11, número 21, agosto-diciembre Sección: Ciencias Administrativas

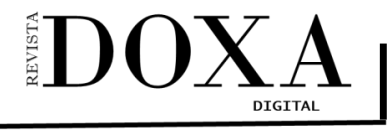

DOI: $10.52191 /$ rdojs.2021.231

Pág.:95-111
Ismael Narciso Jiménez y

Luis Carlos Romero Rodríguez

El derecho al alumbrado público ...

Conforme a este principio fundamental del Derecho Fiscal previsto en el artículo 31, fracción IV de la Constitución Política de los Estados Unidos Mexicanos, el Municipio de Juárez viola contundentemente la esencia de la norma tributaria máxima respectiva, al imponer una Tarifa o cuotas por el Derecho de Alumbrado Público en su ley de Ingresos para el ejercicio fiscal 2021, de manera arbitraria y sin ningún acatamiento al Estado de Derecho primordial, ya que la tarifa impuesta actualmente no cumple con los criterios de proporcionalidad como tal, misma que ha sido comentado en este documento en el punto 3, tabla 1.

La Real Academia Española (2021) define el concepto de "proporcionalidad" como sigue: "Conformidad o proporción de unas partes con el todo o de cosas relacionadas entre sí".

Por otro lado el diccionario jurídico coordinado por Oscar Montoya Pérez, con Número de Registro: 03-2016-053009540100-01, especifica lo siguiente:

La proporcionalidad consiste, en esencia, en que los sujetos pasivos deben contribuir a los gastos públicos en función de su capacidad económica debiendo fijarse los gravámenes de tal manera que las personas que obtengan ingresos elevados tributen en forma cualitativa (sic, debe ser cuantitativa) superior a los de medianos y reducidos recursos, lo que se logra a través de las tarifas progresivas (Montoya, 2021).

Por lo anterior queda de manifiesto que la Tarifa o cuotas de imposición por el Derecho de Alumbrado Público en el Municipio de Juárez actualmente no cumple con el criterio de proporcionalidad ya que ni es progresiva, ni sus partes son en proporción con el todo.

Fundamentando el argumento de lo expuesto en el párrafo anterior queda de manifiesto en lo reiterado por la Suprema Corte de Justicia de la Nación (SCJN) respecto del caso resuelto por el Primer Tribunal Colegiado del Vigésimo Segundo Circuito, respecto del amparo contra leyes del Municipio de Corregidora, Querétaro, publicado el viernes 03 de octubre de 2014 a las 09:30 horas en el Semanario Judicial de la Federación, que a la letra dice:

IMPUESTO PREDIAL. EL ARTÍCULO 13 DE LA LEY DE INGRESOS DEL MUNICIPIO DE CORREGIDORA, QUERÉTARO, PARA EL EJERCICIO FISCAL 2014 AL ESTABLECER UNA TARIFA PROGRESIVA PARA EL COBRO DEL IMPUESTO RESPETA EL PRINCIPIO DE PROPORCIONALIDAD TRIBUTARIA.

El artículo 13 de la Ley de Ingresos del Municipio de Corregidora, Querétaro, para el ejercicio fiscal 2014, que establece una tarifa progresiva para el cobro del impuesto predial, es acorde al principio de proporcionalidad tributaria, porque si bien genera un impacto diferenciado, la distinción realizada por el legislador permite que el cobro del tributo se aproxime en mayor medida a 
Año 16, Vol. 11, número 21, agosto-diciembre Sección: Ciencias Administrativas

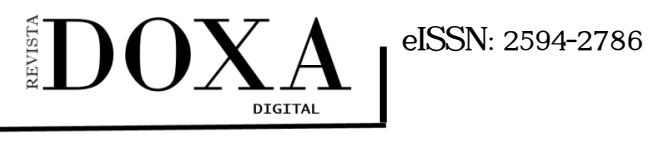

DOI: $10.52191 /$ rdojs.2021.231

Pág.:95-111
Ismael Narciso Jiménez y

Luis Carlos Romero Rodríguez

El derecho al alumbrado público ...

la capacidad del contribuyente, gracias a una tabla con categorías, cuyo criterio de segmentación obedece al aumento de la base gravable, además cada una está definida por un límite mínimo y otro máximo, con una cuota fija para el límite inferior y una tasa aplicable sobre el excedente. La utilización de este mecanismo permite una cuantificación efectiva del tributo que asciende proporcionalmente tanto entre quienes integran una misma categoría como entre aquellos que se ubiquen en las restantes.

PRIMER TRIBUNAL COLEGIADO DEL VIGÉSIMO SEGUNDO CIRCUITO.

Amparo en revisión 188/2014. Gobernador Constitucional del Estado de Querétaro. 5 de junio de 2014. Unanimidad de votos. Ponente: Carlos Hernández García. Secretario: Armando Antonio Badillo García.

Amparo en revisión 189/2014. Gobernador Constitucional del Estado de Querétaro. 12 de junio de 2014. Unanimidad de votos. Ponente: María del Carmen Sánchez Hidalgo. Secretario: Günther Demián Hernández Núñez.

Amparo en revisión 238/2014. Gobernador Constitucional del Estado de Querétaro. 26 de junio de 2014. Unanimidad de votos. Ponente: Alma Rosa Díaz Mora. Secretario: José Francisco Chávez García.

Amparo en revisión 241/2014. Gobernador Constitucional del Estado de Querétaro. 26 de junio de 2014. Unanimidad de votos. Ponente: Carlos Hernández García. Secretario: Alfredo Echavarría García.

Amparo en revisión 217/2014. Gobernador Constitucional del Estado de Querétaro. 3 de julio de 2014. Unanimidad de votos. Ponente: María del Carmen Sánchez Hidalgo. Secretario: Crescenciano Muñoz Gaytán." (SCJN, 2014).

Tabla 2. Tarifa progresiva del artículo 13 de la Ley de Ingresos del Municipio de Corregidora, Querétaro, para el ejercicio fiscal 2014

\begin{tabular}{|c|c|c|c|c|c|c|}
\hline \multirow{2}{*}{$\begin{array}{l}\text { No. de } \\
\text { rango }\end{array}$} & \multicolumn{4}{|c|}{ Rango de Valores Catastrales } & \multirow{2}{*}{ Cuota fija VSMGZ } & \multirow{2}{*}{$\begin{array}{c}\text { Tarifa sobre el exce- } \\
\text { dente del límite infe- } \\
\text { rior } \\
\end{array}$} \\
\hline & & Inferior & & uperior & & \\
\hline 1 & $\$$ & - & $\$$ & $38,946.00$ & 1.00 & 0.00079 \\
\hline 2 & $\$$ & $38,946.01$ & $\$$ & $54,524.40$ & 1.50 & 0.00296 \\
\hline 3 & $\$$ & $54,524.41$ & $\$$ & $76,334.16$ & 2.25 & 0.00317 \\
\hline 4 & $\$$ & $76,334.17$ & $\$$ & $106,867.82$ & 3.38 & 0.00339 \\
\hline 5 & $\$$ & $106,867.83$ & $\$$ & $149,614.95$ & 5.06 & 0.00363 \\
\hline 6 & $\$$ & $149,614.96$ & $\$$ & $209,460.94$ & 7.59 & 0.00389 \\
\hline 7 & $\$$ & $209,460.95$ & $\$$ & $293,245.31$ & 11.39 & 0.00417 \\
\hline 8 & $\$$ & $293,245.32$ & $\$$ & $410,543.43$ & 17.09 & 0.00447 \\
\hline 9 & $\$$ & $410,543.44$ & $\$$ & $574,760.81$ & 25.63 & 0.00479 \\
\hline 10 & $\$$ & $574,760.82$ & $\$$ & $804,665.13$ & 38.44 & 0.00513 \\
\hline 11 & $\$$ & $804,665.14$ & $\$$ & $1,126,531.18$ & 57.67 & 0.00550 \\
\hline 12 & $\$$ & $1,126,531.19$ & $\$$ & $1,577,143.65$ & 86.50 & 0.00589 \\
\hline 13 & $\$$ & $1,577,143.66$ & $\$$ & $2,208,001.11$ & 129.75 & 0.00631 \\
\hline 14 & $\$$ & $2,208,001.12$ & $\$$ & $3,091,201.56$ & 194.62 & 0.00676 \\
\hline 15 & $\$$ & $3,091,201.57$ & $\$$ & $4,327,682.18$ & 291.93 & 0.00725 \\
\hline 25 & $\$$ & $89,414,443.96$ & & adelante & $16,834.11$ & 0.00140 \\
\hline
\end{tabular}

Fuente: Elaboración propia a partir de datos consultados en la Ley de Ingresos del Municipio de Corregidora, Querétaro, para el ejercicio fiscal 2014 
Año 16, Vol. 11, número 21, agosto-diciembre Sección: Ciencias Administrativas

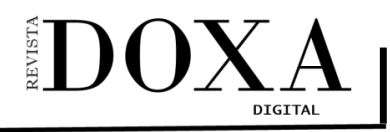

DOI: 10.52191/rdojs.2021.231

Pág.:95-111
Ismael Narciso Jiménez y

Luis Carlos Romero Rodríguez

El derecho al alumbrado público ...

Es decir; la estructura de una tabla progresiva debe ser tal como lo estipulado en el artículo 13 de la "Ley de Ingresos del Municipio de Corregidora, Querétaro, para el ejercicio fiscal 2014", del cual se desprendió lo resuelto por el Primer Tribunal Colegiado del Vigésimo Segundo Circuito de la Suprema Corte de Justicia de la Nación, misma que deja con antelación lo afirmado en cuanto a la violación del principio de proporcionalidad tributaria, el cual se ejemplifica en la tabla 2, como tal:

En cuanto a la determinación de los sujetos pasivos en materia de alumbrado público por el mismo municipio en comento, el artículo 28 , numeral 4 , incisos b) y c) de la "Ley de Ingresos del Municipio de Corregidora, Querétaro, para el ejercicio fiscal 2019", especifica las tablas progresivas siguientes como sigue:

Tabla 3. Importe en fraccionamientos

\begin{tabular}{ll}
\hline \multicolumn{1}{c}{ TIPO DE FRACCIONAMIENTO } & IMPORTE \\
\hline Habitacional & $\$ 1,390.00$ \\
Habitacional Mixto & $\$ 1,200.00$ \\
Comercio y Servicios & $\$ 1,940.00$ \\
Industrial & $\$ 3,660.00$ \\
Otros usos no especificados & $\$ 2,160.00$ \\
\hline
\end{tabular}

Fuente: Ley de Ingresos del Municipio de Corregidora, Querétaro, para el ejercicio fiscal 2019

Tabla 4. Importe en condominios

Fuente: Ley de Ingresos del Municipio de Corregidora, Querétaro, para el ejercicio fiscal 2019

\begin{tabular}{lr}
\hline TIPO DE FRACCIONAMIENTO & IMPORTE \\
\hline Habitacional & $\$ 230.00$ \\
Habitacional Mixto & $\$ 340.00$ \\
Comercio y Servicios & $\$ 460.00$ \\
Industrial & $\$ 870.00$ \\
Otros usos no especificados & $\$ 460.00$ \\
\hline
\end{tabular}

Fuente: Ley de Ingresos del Municipio de Corregidora, Querétaro, para el ejercicio fiscal 2019

Por lo antes expuesto es posible observar que las tablas progresivas deben apegarse al criterio de segmentación en donde debe existir un límite mínimo y otro máximo y la base gravable debe ir incrementándose, ya que esta situación permite una cuantificación efectiva del tributo que ascien- 
Año 16, Vol. 11, número 21, agosto-diciembre Sección: Ciencias Administrativas

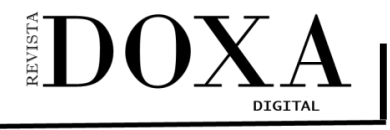

DOI: $10.52191 /$ rdojs.2021.231

Pág.:95-111
Ismael Narciso Jiménez y

Luis Carlos Romero Rodríguez

El derecho al alumbrado público ...

de proporcionalmente tanto entre quienes integran una misma categoría como entre aquellos que se ubiquen en las restantes, en estricto apego al criterio sustentado por el Primer Tribunal Colegiado del Vigésimo Segundo Circuito de la Suprema Corte de Justicia de la Nación, mismo que ha sido objeto de análisis en párrafos anteriores.

\section{Violación al principio de Equidad Tributaria}

Partiendo de la definición del principio de equidad tributaria, como aquel principio derivado del valor justicia en virtud del cual por mandato Constitucional (art. 31, fracción IV), y en estricto apego a la interpretación jurídica, las leyes tributarias deben otorgar un tratamiento igualitario a todos los contribuyentes de un mismo crédito fiscal en todos los aspectos de la relación tributaria (hipótesis de causación, objeto, base, fecha de pago, gastos deducibles, etc.).

Si nos remontamos a datos históricos los antecedentes de esta garantía lo podemos encontrar incluso en la Constitución Política de la Monarquía Española o Constitución de Cádiz (1812), que en su artículo 339 que establecía: "Las contribuciones se repartirán entre todos los españoles en proporción a sus facultades, sin excepción ni privilegio alguno".

Conforme a los cánones de este principio, los impuestos deben fijarse de acuerdo con el porte económico de cada sujeto pasivo, es decir; su capacidad contributiva, de manera tal que los sujetos que obtengan ingresos elevados tributen en forma específica superior a los de medianos y reducidos recursos.

El cumplimiento de este principio se logra a través de tarifas progresivas, pues mediante ellas se consigue que los contribuyentes de más elevados peculios cubran una tributación en monto superior analógicamente hablando.

Abundando; la segunda sala de la Suprema Corte de Justicia de la Nación (SCJN) ha reiterado en la Jurisprudencia Constitucional no. 27844, décima época, publicado el viernes 25 de mayo de 2018 10:30 horas, conforme a la letra:

IGUALDAD O EQUIDAD TRIBUTARIA. LOS CONCEPTOS DE VIOLACIÓN O AGRAVIOS EN LOS QUE SE HAGA VALER LA VIOLACIÓN A DICHOS PRINCIPIOS, SON INOPERANTES SI NO SE PROPORCIONA UN TÉRMINO DE COMPARACIÓN IDÓNEO PARA DEMOSTRAR QUE LA NORMA IMPUGNADA OTORGA UN TRATO DIFERENCIADO.

Para llevar a cabo un juicio de igualdad o equidad tributaria es necesario contar con un punto de comparación, es decir, con algún parámetro que permita medir a las personas, objetos o magnitudes entre las cuales se afirma existe un trato desigual, en razón de que el 
Año 16, Vol. 11, número 21, agosto-diciembre Sección: Ciencias Administrativas

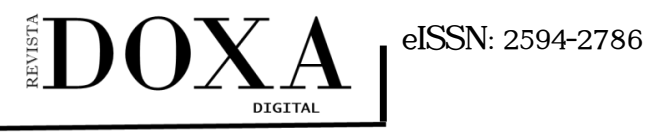

DOI: $10.52191 /$ rdojs.2021.231

Pág.:95-111
Ismael Narciso Jiménez y

Luis Carlos Romero Rodríguez

El derecho al alumbrado público ...

derecho a la igualdad es fundamentalmente instrumental y siempre se predica respecto de algo. En ese sentido, la carga argumentativa de proponer el término de comparación implica que sea idóneo, pues debe permitir que efectivamente se advierta la existencia de algún aspecto homologable, semejante o análogo entre los elementos comparados. Así, de no proporcionarse el punto de comparación para medir un trato disímil o que éste no sea idóneo, el concepto de violación o agravio en el que se haga valer la violación al principio de igualdad o equidad tributaria deviene en inoperante.

Amparo en revisión 441/2015. Smart \& Final del Noroeste, S.A. de C.V. y otra. 5 de octubre de 2016. Cinco votos de los Ministros Eduardo Medina Mora I., Javier Laynez Potisek, José Fernando Franco González Salas, Margarita Beatriz Luna Ramos y Alberto Pérez Dayán; votó en contra de consideraciones Margarita Beatriz Luna Ramos. Ponente: Javier Laynez Potisek. Secretario: Jorge Jiménez Jiménez.

Amparo en revisión 845/2015. Tiendas Aurrerá, S. de R.L. de C.V. 5 de octubre de 2016. Cinco votos de los Ministros Eduardo Medina Mora l., Javier Laynez Potisek, José Fernando Franco González Salas, Margarita Beatriz Luna Ramos y Alberto Pérez Dayán; votó en contra de consideraciones Margarita Beatriz Luna Ramos. Ponente: Javier Laynez Potisek. Secretario: Jorge Jiménez Jiménez. Amparo en revisión 876/2015. Desarrollo Comercial Abarrotero, S.A. de C.V. y otras. 25 de enero de 2017. Cinco votos de los Ministros Alberto Pérez Dayán, Javier Laynez Potisek, José Fernando Franco González Salas, Margarita Beatriz Luna Ramos y Eduardo Medina Mora I.; votó en contra de consideraciones Margarita Beatriz Luna Ramos. Ponente: Javier Laynez Potisek. Secretario: Jorge Jiménez Jiménez.

Amparo en revisión 403/2017. Servicios Integrales Merza, S.A. de C.V. 30 de agosto de 2017. Cinco votos de los Ministros Alberto Pérez Dayán, Javier Laynez Potisek, José Fernando Franco González Salas, Margarita Beatriz Luna Ramos y Eduardo Medina Mora I. Ponente: Alberto Pérez Dayán. Secretario: Jorge Jiménez Jiménez.

Amparo directo en revisión 4687/2017. Volkswagen de México, S.A. de C.V. 18 de abril de 2018. Unanimidad de cuatro votos de los Ministros Alberto Pérez Dayán, Javier Laynez Potisek, José Fernando Franco González Salas y Eduardo Medina Mora I. Ponente: Margarita Beatriz Luna Ramos; en su ausencia hizo suyo el asunto Alberto Pérez Dayán. Secretaria: Claudia Mendoza Polanco.

Tesis de jurisprudencia 54/2018 (10a.). Aprobada por la Segunda Sala de este Alto Tribunal, en sesión privada del nueve de mayo de dos mil dieciocho." SCJN, (2018).

Es decir, el Municipio de Juárez viola de manera fehaciente este principio al no considerar en sus cuotas impositivas un término de comparación respecto de los sujetos pasivos considerados en

Tabla 5. Clasificación de asentamientos humanos

$\begin{array}{lll}\text { Aeropuerto } & \text { Ampliación } & \text { Barrio } \\ \text { Cantón } & \text { Ciudad } & \text { Ciudad Industrial } \\ \text { Colonia } & \text { Condominio } & \text { Conjunto Habitacional } \\ \text { Corredor Industrial } & \text { Coto } & \text { Cuartel } \\ \text { Ejido } & \text { Ex hacienda } & \text { Fracción } \\ \text { Fraccionamiento } & \text { Granja } & \text { Hacienda } \\ \text { Ingenio } & \text { Manzana } & \text { Paraje } \\ \text { Parque Industrial } & \text { Privada } & \text { Prolongación } \\ \text { Pueblo } & \text { Puerto } & \text { Ranchería } \\ \text { Rancho } & \text { Región } & \text { Residencial } \\ \text { Rinconada } & \text { Sección } & \text { Sector } \\ \text { Supermanzana } & \text { Unidad } & \text { Unidad Habitacional } \\ \text { Villa } & \text { Zona Federal } & \text { Zona Industrial } \\ \text { Zona Militar } & \text { Zona Naval } & \end{array}$

Fuente: Elaboración propia a partir de datos consultados en el INEGI 
Año 16, Vol. 11, número 21, agosto-diciembre Sección: Ciencias Administrativas

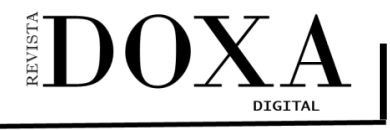

DOI: 10.52191/rdojs.2021.231

Pág.:95-111
Ismael Narciso Jiménez y

Luis Carlos Romero Rodríguez

El derecho al alumbrado público ...

la tabla 1. Por otro lado, el Instituto Nacional de Estadística y Geografía (INEGI) en su Norma Técnica para Domicilios Geográficos, establece los conceptos sobre la clasificación de los asentamientos humanos en el territorio mexicano mismo que se desglosa en la tabla 5 . Esto con la finalidad de que dicho municipio tome como base los conceptos técnicos de clasificación, delimitando los sujetos pasivos y los adapte a la realidad de la zona en sus cuotas impositivas, con un criterio técnico fiscal y en estricto apego al Estado de Derecho.

Dicha información citada con antelación resulta obligatorio para el Municipio de Juárez, de conformidad con el artículo $6^{\circ}$ de la Ley del Sistema Nacional de Información Estadística y Geográfica (2021), que a continuación se transcribe: "La Información de Interés Nacional será oficial y de uso obligatorio para la Federación, los estados, el Distrito Federal y los municipios. ...."

Cabe advertir que es inaplazable la imperiosa necesidad de emprender un plan de trabajo enfocado a adecuar las normas fiscales del Municipio de Juárez en materia de Derecho de Alumbrado Público, con criterios técnicos, fiscales y sin vulnerar el Estado de Derecho en materia tributaria.

\section{Conclusiones y recomendaciones}

Cuando no se tiene la visión técnica e integral, necesaria para conducir adecuadamente el desarrollo institucional, y se carece de una formación profesional orientada al orden y la disciplina administrativos en materia de recaudación de ingresos, se improvisan cambios al marco jurídico y, consecuentemente, éste se va impregnando de incongruencias que es muy complicado corregir, pero no imposible; como sucede actualmente en el gobierno municipal de Juárez.

La eficiencia en la recaudación y/o captación de ingresos es un aspecto esencial en toda organización sea del ámbito público o privado, y un elemento indispensable para alcanzar los objetivos planteados en todo plan de trabajo. En este caso el Municipio de Juárez no es la excepción, ya que para poder ejercitar la facultad económica - coactiva necesita estar en estricto apego a los principios generales del derecho acorde al cual las autoridades sólo pueden hacer aquello para lo que expresamente les facultan las leyes, en el entendido de que éstas, a su vez, constituyen la manifestación de la voluntad general, de lo contrario se vulnera el derecho a la seguridad jurídica de los contribuyentes y el acto de autoridad se considerará arbitrario.

La conclusión de la idea central axiomática del presente trabajo de investigación es que el gobierno municipal de Juárez debe establecer las estrategias y la necesidad de instituir a un equipo de 
Año 16, Vol. 11, número 21, agosto-diciembre Sección: Ciencias Administrativas

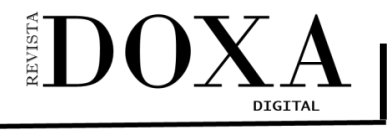

DOI: 10.52191/rdojs.2021.231

Pág.:95-111
Ismael Narciso Jiménez y

Luis Carlos Romero Rodríguez

El derecho al alumbrado público ...

trabajo, capaces de garantizar las reformas legales adecuadas para actualizar el marco jurídico municipal; en este caso específico en materia de Derecho de Alumbrado Público y por ende de manera general en materia de recaudación de ingresos.

Es decir; la administración municipal debe alcanzar una administración de calidad y acceder a un esquema de gobierno competitivo y eficaz, que permita lograr un mejor cumplimiento en la satisfacción de las demandas sociales, mediante una captación eficiente de los recursos pecuniarios, ya que como tal el derecho al cobro del DAP le asiste por mandato Constitucional.

De manera reiterativa y tajante; es inaplazable para el Municipio de Juárez la imperiosa necesidad de emprender un plan de trabajo enfocado a adecuar las normas tributarias, no únicamente en el ámbito del Derecho de Alumbrado Público, sino de manera general en el ámbito de su competencia fiscal, sin vulnerar los principios fundamentales del derecho como lo hace actualmente.

A modo de reflexión cito la frase célebre de Fernando Sainz de Bujanda, catedrático de la Universidad Complutense deadrid y creador de los estudios de derecho financiero y tributario en España,

No es posible que el hombre de nuestros días crea en el estado de Derecho en que vive, ni contribuya con lealtad y diligencia al levantamiento de las cargas públicas, si la Administración no somete rigurosamente sus actos fiscales a un orden jurídico que infunda seguridad en sus relaciones con las economías particulares. ¡Cuántas veces el fraude no es sino una torpe y amarga reacción frente a un Estado en el que se ha perdido la fé!

\section{Referencias}

Anexo de la Ley de Ingresos del Municipio de Juárez para el ejercicio fiscal 2021.Secretaría de Gobierno del Estado de Chihuahua (Municipio de Juárez). Periódico Oficial del Estado (POE) No. 04, publicado el 13 de enero de 2021. Cámara de Diputados del H. Congreso del Estado de Chihuahua. http://www.congresochihuahua2.gob.mx/biblioteca/leyes/ngresos/ archivos/1778.pdf.

Código Municipal para el Estado de Chihuahua. Secretaría de Gobierno del Estado de Chihuahua. Periódico Oficial del Estado (POE). Publicado en el POE No. 92 del 18 de noviembre de 1995, última reforma POE 2021.08.28/No. 69, Cámara de Diputados del H. Congreso del Estado de Chihuahua. http://www.congresochihuahua2.gob.mx/biblioteca/codigos/ archivosCodigos/19.pdf. 
Año 16, Vol. 11, número 21, agosto-diciembre Sección: Ciencias Administrativas

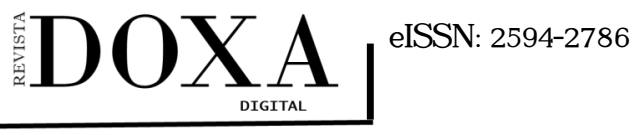

DOI: $10.52191 /$ rdojs.2021.231

Pág.:95-111
Ismael Narciso Jiménez y

Luis Carlos Romero Rodríguez

El derecho al alumbrado público ...

Código Fiscal de la Federación. Estados Unidos Mexicanos. Diario Oficial de la Federación (DOF). Nuevo Código Publicado en el DOF el 31 de diciembre de 1981, última reforma 31 de julio de 2021. Cámara de Diputados del H. Congreso de la Unión. http://www.diputados.gob.mx/ LeyesBiblio/pdf/8 310721.pdf

Constitución Política de los Estados Unidos Mexicanos. Diario Oficial de la Federación. Constitución publicada en el DOF el 5 de febrero de 1917, última reforma 28 de mayo de 2021.Cámara de Diputados del H. Congreso de la Unión. http://www.diputados.gob.mx/LeyesBiblio/ pdf/1 280521.pdf.

Constitución Política de la Monarquía Española. Boletín Oficial del Estado. Promulgada el 19 de marzo 1812. Cortes Generales y Extraordinarias de España. http://www.cepc.gob.es/docs/ constituciones-espa/1812.pdf?sfvrsn=2

Definición ABC (2021). Definición de alumbrado. En diccionario de la web Definición ABC. Florencia, Italia: https://www.definicionabc.com/general/alumbrado.php.

Instituto Nacional de Estadística Geografía e Informática (INEGI), (2010). Norma Técnica para Domicilios Geográficos. Diario Oficial de la Federación (DOF). Publicado el viernes 12 de noviembre de $2010 . \quad$ https://www.inegi.org.mx/inegi/spc/doc/INTERNET/ MANUAL NORMA TECNICA DOMS.pdf.

Jasso López, L. C. (2015). ¿Por qué la gente se siente insegura en el espacio público? [tesis doctoral, Centro de Investigación y Docencia Económicas, A. C. (CIDE)]. Repositorio institucional CIDE. bitstream/1011/684/1/000145898 documento.pdf

https://cide.repositorioinstitucional.mx/jspui/

Ley de Ingresos del Municipio de Corregidora, Querétaro, para el ejercicio fiscal 2014 (2014).Secretaría de Gobierno del Estado de Querétaro. Periódico Oficial del Estado (POE), s/f de publicación. Poder Legislativo del Estado de Querétaro. https:// www.corregidora.gob.mx/Documentos/2015-2018/Protal Fiscal/I/T.T.I.P 2014.pdf.

Ley de Ingresos del Municipio de Corregidora, Querétaro, para el ejercicio fiscal 2019. (2019). Secretaría de Gobierno del Estado de Querétaro. Periódico Oficial del Estado (POE), s/f de publicación. Poder Legislativo del Estado de Querétaro. https://www.corregidora.gob.mx/ Documentos/2018-2021/Transparencia/art66/Anexos/Ayuntamiento///NORMATIVIDAD 2019/ Ley de Ingresos 2019.pdf

Ley de Ingresos del Municipio de Juárez para el ejercicio fiscal 2021. Secretaría de Gobierno del Estado de Chihuahua (Municipio de Juárez). Periódico Oficial del Estado (POE) No. 105, publicado el 30 de diciembre de 2020. Cámara de Diputados del H. Congreso del Estado de Chihuahua. http://www.congresochihuahua2.gob.mx/biblioteca/leyes/ngresos/ archivos/1732.pdf. 
Año 16, Vol. 11, número 21, agosto-diciembre

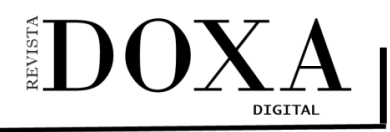

Sección: Ciencias Administrativas

DOI: 10.52191/rdojs.2021.231

Pág.:95-111
Ismael Narciso Jiménez y

Luis Carlos Romero Rodríguez

El derecho al alumbrado público ...

Ley del Impuesto al Valor Agregado (2021). Estados Unidos Mexicanos. Diario Oficial de la Federación (DOF). Nueva Ley publicada en el DOF el 29 de diciembre de 1978, última reforma 31 de julio de 2021. Cámara de Diputados del H. Congreso de la Unión. http:// www.diputados.gob.mx/LeyesBiblio/pdf/77 310721.pdf.

Ley del Sistema Nacional de Información Estadística y Geográfica. Estados Unidos Mexicanos. Diario Oficial de la Federación (DOF). Nueva Ley publicada en el DOF el 16 de abril de 2008, última reforma 20 de mayo de 2021. Cámara de Diputados del H. Congreso de la Unión. http://www.diputados.gob.mx/LeyesBiblio/pdf/LSNIEG 200521.pdf.

Municipio de Juárez (Chihuahua), (2021). Categoría: Municipios del estado de Chihuahua. Municipio de Juárez. https://juarez.gob.mxl.

Montoya Pérez, O. (2021). Principio de proporcionalidad. En Diccionario Jurídico. Ciudad de México. Estados Unidos Mexicanos. http://diccionariojuridico.mx/autor/oscar-montoya-perez/.

Real Academia Española (RAE), (2021). Definición de alumbrado. En Diccionario de la lengua española (23. ${ }^{a}$ edición). Madrid, España: https://dle.rae.es/alumbrado.

Real Academia Española (RAE), (2021). Definición de proporcionalidad. En Diccionario de la lengua española (23. ${ }^{a}$ edición). Madrid, España: https://dle.rae.es/proporcionalidad.

Suprema Corte de justicia de la Nación (14 de junio de 2017). Estados Unidos Mexicanos. Amparo directo en revisión 6718/2016. Gaceta del Semanario Judicial de la Federación. https:// sjf2.scjn.gob.mx/detalle/tesis/2016003.

Suprema Corte de justicia de la Nación (03 de octubre de 2014). Estados Unidos Mexicanos Amparo en revisión 217/2014. Gaceta del Semanario Judicial de la Federación. https:// sjf.scjn.gob.mx/SJFSem/Paginas/DetalleGeneralScroll.aspx?

$\underline{i d=25256 \& \text { Clase }=\text { DetalleTesisEjecutorias }}$

Suprema Corte de justicia de la Nación (25 de mayo de 2018). Estados Unidos Mexicanos. Amparo en revisión 441/2015. Gaceta del Semanario Judicial de la Federación. https:// sjf.scjn.gob.mx/SJFSem/Paginas/DetalleGeneralScroll.aspx? $\underline{\text { id }=27844 \& \text { Clase }=\text { DetalleTesisEjecutorias. }}$. 